\title{
Relationships Between Verticillium dahliae Inoculum Density and Wilt Incidence, Severity, and Growth of Cauliflower
}

\author{
C. L. Xiao and K. V. Subbarao
}

Department of Plant Pathology, University of California, Davis, c/o U.S. Agricultural Research Station, Salinas 93905.

Current address of C. L. Xiao: Department of Plant Pathology, University of California, One Shields Avenue, Davis 95616. Accepted for publication 15 July 1998.

\begin{abstract}
Xiao, C. L., and Subbarao, K. V. 1998. Relationships between Verticillium dahliae inoculum density and wilt incidence, severity, and growth of cauliflower. Phytopathology 88:1108-1115.

Microplot and field experiments were conducted to evaluate the effects of inoculum density on Verticillium wilt and cauliflower growth. Soil containing Verticillium dahliae microsclerotia was mixed with various proportions of fumigated soil to establish different inoculum densities (fumigated soil was used as the noninfested control). Seven inoculum density treatments replicated four times were established, and the treatments were arranged in a randomized complete block design. Soil was collected from each microplot immediately after soil infestation for $V$. dahliae assay by plating onto sodium polypectate agar (NP-10) selective medium using the Anderson sampler technique. Five-week-old cauliflower was transplanted into two beds within each $1.2-$ by $1.2-\mathrm{m}$ microplot. At the same time, several extra plants were also transplanted at the edge of each bed for destructive sampling to examine the disease onset (vascular discoloration) after planting. Cauliflower plants were monitored for Verticillium wilt development. Stomatal resistance in two visually healthy upper and two lower, diseased leaves in each microplot was measured three times at

height, number of leaves, and dry weights of leaves and roots were determined. The higher the inoculum density, the earlier was disease onset. A density of 4 microsclerotia per g of dry soil caused $16 \%$ wilt incidence, but about 10 microsclerotia per g of soil caused $50 \%$ wilt incidence. Both wilt incidence and severity increased with increasing inoculum density up to about 20 microsclerotia per g of soil, and additional inoculum did not result in significantly higher disease incidence and severity. A negative exponential model described the disease relationships to inoculum levels under both microplot and field conditions. Stomatal resistance of diseased leaves was significantly higher at higher inoculum densities; in healthy leaves, however, no treatment differences occurred. The height, number of leaves, and dry weights of leaves and roots of plants in the fumigated control were significantly higher than in infested treatments, but the effects of inoculum density treatments were variable between years. Timing of cauliflower infection, crop physiological processes related to hydraulic conductance, and wilt intensity (incidence and severity) were thus affected by the inoculum density. Verticillium wilt management methods used in cauliflower should reduce inoculum density to less than four microsclerotia per $g$ of soil to produce crops with the fewest number of infected plants.
\end{abstract} weekly intervals after initial wilt symptoms occurred. At maturity, all plants were uprooted, washed free of soil, and wilt incidence and severity, plant

Verticillium dahliae Kleb., the causal agent of wilt on many economically important crops, is a soilborne pathogen with worldwide distribution. The fungus can survive as microsclerotia in soil for up to 13 years (26). Microsclerotia in soil have been considered as the principal source of inoculum for wilt development in all hosts. Microsclerotia are stimulated to germinate in rhizosphere soil or its vicinity by root exudates, penetrate plant roots, and move to the vascular tissues (26). Because Verticillium wilt is a monocyclic disease, inoculum levels of $V$. dahliae (microsclerotia per g of soil) in the soil at planting play a critical role in wilt development on many crops $(2,3,14,15,20,21,24)$. Understanding relationships between inoculum density in soil at planting and wilt development is, therefore, essential for developing a disease risk assessment based on preplant soil assays $(11,15)$. Also, inoculum density can be an important factor in determining when control practices should be initiated, their nature, and their duration $(12,23)$. For example, crop rotation is used to reduce the number of $V$. dahliae microsclerotia in soil and to reduce wilt incidence (number of plants with wilt symptoms expressed as a percentage of the total) in certain crops $(9,23,29)$. Short-term crop rotations cannot successfully control $V$. dahliae, because the numbers of microsclerotia after a short-term rotation usually remain above the threshold, resulting

Corresponding author: K. V. Subbarao; E-mail address: kvsubbarao@ucdavis.edu

Publication no. P-1998-0821-01R

(C) 1998 The American Phytopathological Society
Additional keywords: soilborne diseases. in significant crop losses $(9,23)$. Therefore, the length of rotation needed for effective Verticillium wilt control depends on inoculum levels after rotation. Quantitative information on the relationship between inoculum density in soil and wilt development can be used as a basis for determining the relative length of rotation with certain crops.

In general, Verticillium wilt incidence and severity (relative degree of vascular discoloration and the height to which it had progressed in infected plants expressed in percentages) increase as inoculum density of $V$. dahliae in soil increases. In California cotton fields, the number of plants infected by $V$. dahliae at the end of the crop season is directly related to the density of microsclerotia in soil $(2,21,24)$. The rate of colonization of potato stems by $V$. dahliae is related to the initial soil population in potato early dying (20). The minimum number of microsclerotia in soil required to cause wilt is crop specific, and the proportion of infected plants with increasing density is also crop dependent. For example, in tomato, 0.5 microsclerotia per $\mathrm{g}$ of soil caused $50 \%$ wilt incidence, but six microsclerotia per $\mathrm{g}$ of soil could cause $100 \%$ wilt incidence by the end of the growing season (14). In strawberry, 0.3 microsclerotia per $\mathrm{g}$ of dry soil can cause $5 \%$ Verticillium wilt, and small increases in their numbers in soil can cause the death of a majority of plants (15).

In many crops, wilt-inducing $V$. dahliae causes chlorosis, stunting, premature defoliation, and wilting (26). Verticillium wilt of cotton reduces plant height, lateral branching, and dry matter accumulation in leaves, stems, roots, and bolls in fields (25). Potato plants 
also show reduced leaf area and function (photosynthetic efficiency of leaves) following $V$. dahliae infection due to reduced leaf development, leaf chlorosis, and premature defoliation (16,23). Verticillium wilt results in stunted growth and reduced eggplant yields (13). V. dahliae causes water stress in host plants by decreasing hydraulic conductance of the xylem (26). Stomatal resistance in leaves is a good indicator of physiological responses to $V$. dahliae infection $(7,19,30)$. Studies on physiological responses of cotton (30) and potato (6) plants infected with $V$. dahliae have shown increased stomatal resistance in the leaves of diseased plants. Increased stomatal resistance reduces the concentration of $\mathrm{CO}_{2}$ within leaves and results in decreased net photosynthesis $(6,7)$. The stress induced by multiple infections in the root may be expected to further increase stomatal resistance in infected plants. However, the question of whether the stomatal resistance increases or decreases with inoculum density has not been tested. Information on the relationships between inoculum density, wilt development, and stomatal behavior of leaves is not available for any crop.

Cauliflower (Brassica oleracea L. var. botrytis L.) is an important vegetable crop in coastal California. Commercial cauliflower has been severely affected by $V$. dahliae in recent years. Verticillium wilt of cauliflower causes chlorosis of lower leaves, defoliation, wilting, and vascular discoloration that result in reduced size and quality of the harvested heads (17). Rotation with broccoli is a proven method of Verticillium wilt control in cauliflower $(28,32)$. The length of rotations with broccoli is determined by the levels of $V$. dahliae microsclerotia in the soil. An understanding of the inoculum density-disease incidence relationships would help determine the length of rotations with broccoli based on the yearly rate of inoculum attrition by broccoli. The objectives of this study were to determine relationships between inoculum density of $V$. dahliae in soil at planting and Verticillium wilt onset, incidence, and severity on cauliflower and to determine the effects of Verticillium wilt on stomatal resistance in cauliflower at different inoculum densities. A preliminary report has been published (33).

\section{MATERIALS AND METHODS}

Production of microsclerotia. Production of microsclerotia has been described previously (32). Briefly, 125-ml Erlenmeyer flasks, each containing $50 \mathrm{ml}$ of potato dextrose broth, were inoculated with two 4-mm-diameter culture disks taken from a 4-week-old $V$. dahliae culture on potato dextrose agar. Flasks were incubated on a horizontal shaker for 2 weeks at room temperature $\left(22\right.$ to $\left.24^{\circ} \mathrm{C}\right)$. The conidial suspension was filtered through cheesecloth, and then the density of conidia was adjusted to about $10^{7}$ conidia per ml. Soil that passed through a $0.425-\mathrm{mm}$ sieve was sterilized by autoclaving at $121^{\circ} \mathrm{C}$ for $1 \mathrm{~h}$ twice, on 2 successive days. Each 100 - by $15-\mathrm{mm}$ glass petri plate containing $50 \mathrm{~g}$ of sterilized soil was amended with $20 \mathrm{ml}$ of conidial suspension and incubated on a laboratory bench at room temperature $\left(22\right.$ to $\left.24^{\circ} \mathrm{C}\right)$. Plates with microsclerotia after 10 days of incubation were air-dried for 15 days to kill mycelia and conidia. Microsclerotia produced in the laboratory were thoroughly mixed with naturally $V$. dahliae-infested field soil and used as the inoculum carrier for soil infestation to establish inoculum densities for microplot experiments.

Microplot experiments. Microplots (1.2 by $1.2 \mathrm{~m}$ ) established at the United States Agricultural Research Station in Salinas, CA, were used for this study. The soil used in the experiment was an Antioch sandy loam (sand, 45.8\%; silt, 43.4\%; clay, $8.8 \%$; and organic matter, $1.8 \%$ ) with a $\mathrm{pH}$ of 7.1. Inoculum carrier was mixed with fumigated field soil (fumigated with a 67:33 mixture of methyl bromide and chloropicrin at $337 \mathrm{~kg} \mathrm{ha}^{-1}$ ) in various proportions in a cement mixer for $10 \mathrm{~min}$ to establish different inoculum densities. Fumigated soil was used as a control in which inoculum density was zero microsclerotia per $\mathrm{g}$ of dry soil (undetectable; the minimum number of microsclerotia detectable by an Anderson sampler in this study was two per g of soil). Soil was collected from each microplot immediately after soil infestation for $V$. dahliae assay by plating onto sodium polypectate agar (NP-10) selective medium using the Anderson sampler technique (8). In 1994, seven inoculum density treatments were established, and the average number of microsclerotia in these treatments were $0,6,11,20,31,91$, and 225 per g of dry soil, respectively. The treatments were arranged in a randomized complete block design with four replications (four microplots per treatment). In 1995, the treatments were adjusted based on the results from 1994. Six treatments including $0,4,9$, 16,24 , and 36 microsclerotia per g of dry soil were arranged as in 1994. Five-week-old cauliflower transplants of cultivar White Rock were transplanted at $20-\mathrm{cm}$ spacing on two beds within each microplot on 19 August 1994 and 10 August 1995. At the same time, several extra plants were transplanted at the edge of each bed for destructive sampling at weekly intervals after planting. Cultural practices were followed in accordance with the recommended procedures for the crop (1). The microplots were regularly irrigated in the furrows throughout the experiment. A urea-nitrate fertilizer (Wilbur-Ellis Co., Salinas, CA) was applied to the furrow at the rate of $124 \mathrm{~kg} \mathrm{ha}^{-1}$ at 3-week intervals.

The plants within each microplot were monitored for Verticillium wilt development. The time of disease onset in each treatment was determined by uprooting two plants (the extra plants for destructive sampling) weekly from the edge of beds in each microplot and evaluating vascular discoloration. The first destructive plant samplings for this evaluation occurred on 13 September 1994 and 4 September 1995. Pieces of diseased root and stem tissue from each microplot were surface-sterilized with $0.5 \% \mathrm{NaOCl}$ and plated on NP-10 selective medium and incubated at room temperature $\left(22\right.$ to $\left.24^{\circ} \mathrm{C}\right)$ to verify $V$. dahliae colonization. The plates were examined periodically for the development of $V$. dahliae colonies. The identity of $V$. dahliae was confirmed based on the presence of microsclerotia and conidiophore morphology.

Two visually healthy upper and two lower, disease-induced chlorotic leaves in each microplot were marked, and the stomatal resistance of these leaves was measured systematically using a porometer (Delta-T Devices, Cambridge, England) three times at 1-week intervals after wilt symptoms developed in all treatments. Microplots were watered 1 or 2 days prior to the stomatal resistance measurements to ensure adequate soil moisture. The measurements were only taken on sunny days between 1300 and 1500. For each individual leaf, the mean of five repeated readings of the porometer was used. The porometer readings were converted to leaf stomatal resistance $\left(\mathrm{s} \mathrm{cm}^{-1}\right)$ using a calibration curve from the corresponding day.

At maturity, all plants in each microplot were uprooted, roots were washed free of soil, and plant height and number of leaves were determined for each plant. The stem and root portion of each plant was longitudinally split to estimate the percentage of vascular tissue discolored (wilt severity) on a scale of 0 to 5 , in which $0=$ no discoloration, $1=1$ to $10 \%$ discoloration, $2=11$ to $30 \%$ discoloration, $3=31$ to $50 \%$ discoloration, $4=51$ to $75 \%$ discoloration, and $5=76$ to $100 \%$ discoloration. Wilt incidence was expressed as proportion of plants with vascular discoloration in each microplot. Pieces of diseased root and stem tissue from five plants from each microplot were surface-sterilized, plated on NP-10 selective medium, and incubated at room temperature $\left(22\right.$ to $\left.24^{\circ} \mathrm{C}\right)$. The plates were examined periodically for the development of $V$. dahliae colonies. Subsequent to the disease evaluations, the total dry weights of leaves and roots were determined after oven-drying at $70^{\circ} \mathrm{C}$.

Field surveys. Field surveys were conducted in two commercial fields each in 1994 and 1995 in Salinas, CA. The fields were naturally infested with $V$. dahliae. The soil texture was a silty clay and was similar in the four fields. Cauliflower was annually rotated with lettuce in all four fields. Three 16- by 16-m sites in each field were selected for soil sampling and disease assessment. Five 2- by 
2-m quadrats were marked by an ' $X$ ' pattern in each site for soil sampling and Verticillium wilt assessment. Four soil cores were collected to a depth of $15 \mathrm{~cm}$ from each sampling quadrat and composited into a single sample. Soil was air-dried and assayed

TABLE 1. Initial dates of Verticillium wilt onset on cauliflower under different inoculum densities of Verticillium dahliae in 1994 and 1995

\begin{tabular}{cccccc}
\hline & & \multicolumn{5}{c}{ Days after transplanting } \\
\cline { 3 - 6 } Year & Inoculum $^{\mathrm{y}}$ & $24 / 25$ & $31 / 33$ & $39 / 40$ & $45 / 48$ \\
\hline 1994 & 0 & - & - & - & - \\
& 6 & - & - & - & + \\
& 11 & - & - & + & + \\
& 20 & - & + & + & + \\
& 31 & - & + & + & + \\
& 91 & - & + & + & + \\
1995 & 225 & + & + & + & + \\
& 0 & - & - & - & - \\
& 4 & - & - & - & + \\
& 9 & - & - & + & + \\
& 17 & - & + & + & + \\
& 24 & - & + & + & + \\
& 36 & + & + & + & + \\
\hline
\end{tabular}

$\mathrm{y}$ Inoculum density expressed as number of microsclerotia per $\mathrm{g}$ of dry soil.

${ }^{\mathrm{z}}$ Number of days for 1994/1995. + = Plants with vascular discoloration were observed and $V$. dahliae colonies recovered from plated tissues; $-=$ neither vascular discoloration was observed nor $V$. dahliae recovered. The observations of vascular discoloration were made on eight plants from four replications of each treatment. for $V$. dahliae microsclerotia as described above. After commercial harvest, the total number of plants and plants with vascular discoloration in each sampling quadrat were counted.

Data analyses. Wilt incidence data were arcsine square roottransformed prior to the analysis to normalize variance. Differences in the inoculum density treatments for wilt incidence and severity, plant height, number of leaves, and dry weights of leaves and roots were determined by analysis of variance, and means were compared by the least significant difference test $(P \leq 0.05)$. The relationships between inoculum density and Verticillium wilt incidence and severity were determined by nonlinear regression analysis using PROC NLIN in SAS (release 6.12; SAS Institute, Cary, NC). A negative exponential model was used to describe the relationships between inoculum density and the wilt incidence and severity. Because NLIN is a maximum likelihood procedure and the coefficient of determination for nonlinear regression models is derived indirectly, the relationship between observed and predicted wilt incidence and severity by the model was examined by linear regression analysis using PROC REG in SAS (18). This allowed us to examine the model fitness and derive the coefficient of determination directly.

Repeated measures analysis of variance was used to test stomatal resistance in leaves from different inoculum densities recorded over time using the SAS General Linear Models procedure. Where time and time $\times$ treatment effects were significant, further partitioning of variance into linear, quadratic, and cubic trends were made and tested.
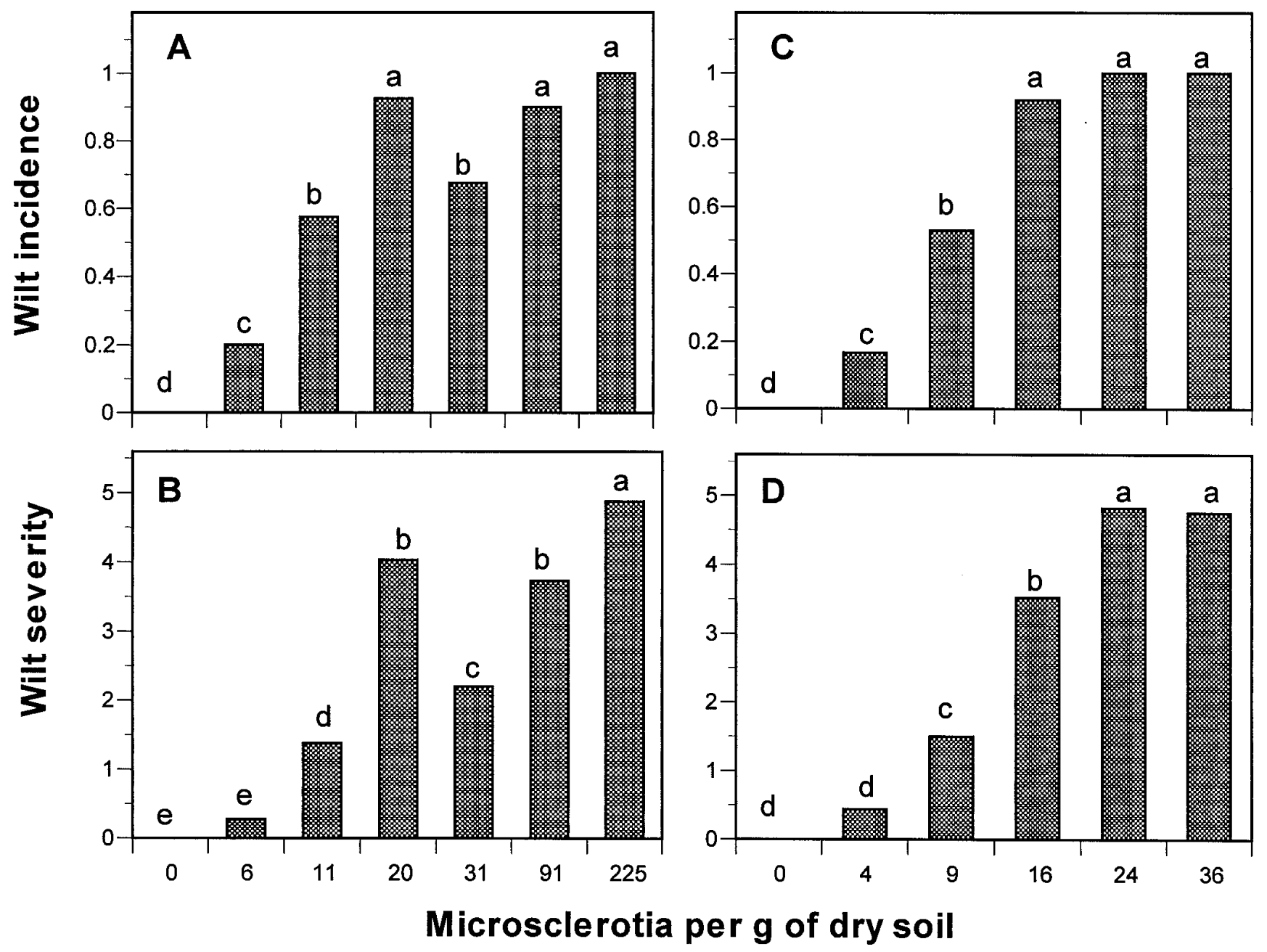

Fig. 1. Relationships between inoculum densities of Verticillium dahliae in soil (microsclerotia per g of dry soil) at planting and Verticillium wilt incidence and severity on cauliflower at maturity from microplot experiments in A and B, 1994; and $\mathbf{C}$ and D, 1995. Microsclerotia produced in the laboratory were used to infest field soil for microplot experiments. V. dahliae was assayed by plating soil onto sodium polypectate agar (NP-10) selective medium using the Anderson sampler technique. Within each panel, columns marked with the same letters are not significantly different according to the least significant difference test $(P \leq 0.05)$. 


\section{RESULTS}

Initial dates of disease onset. An association between increasing inoculum density and disease onset was observed in both years (Table 1). The cause of discoloration in cauliflower plants was confirmed by the recovery of $V$. dahliae colonies from the vascular tissue. The higher the $V$. dahliae inoculum density, the earlier was disease onset in cauliflower plants. At the lowest $V$. dahliae density (non-zero) in both years, the disease did not occur until 6 to 7 weeks after transplanting. In contrast, at the highest inoculum density, $V$. dahliae infection was observed within 3 to 4 weeks after transplanting.

Inoculum density effects on wilt incidence and severity. No vascular discoloration was observed in plants from the fumigated control (zero microsclerotia per g of soil) in both 1994 and 1995 (Fig. 1). Both wilt incidence and severity at harvest time were significantly different between the fumigated control and infested treatments with various levels of $V$. dahliae inoculum density. A
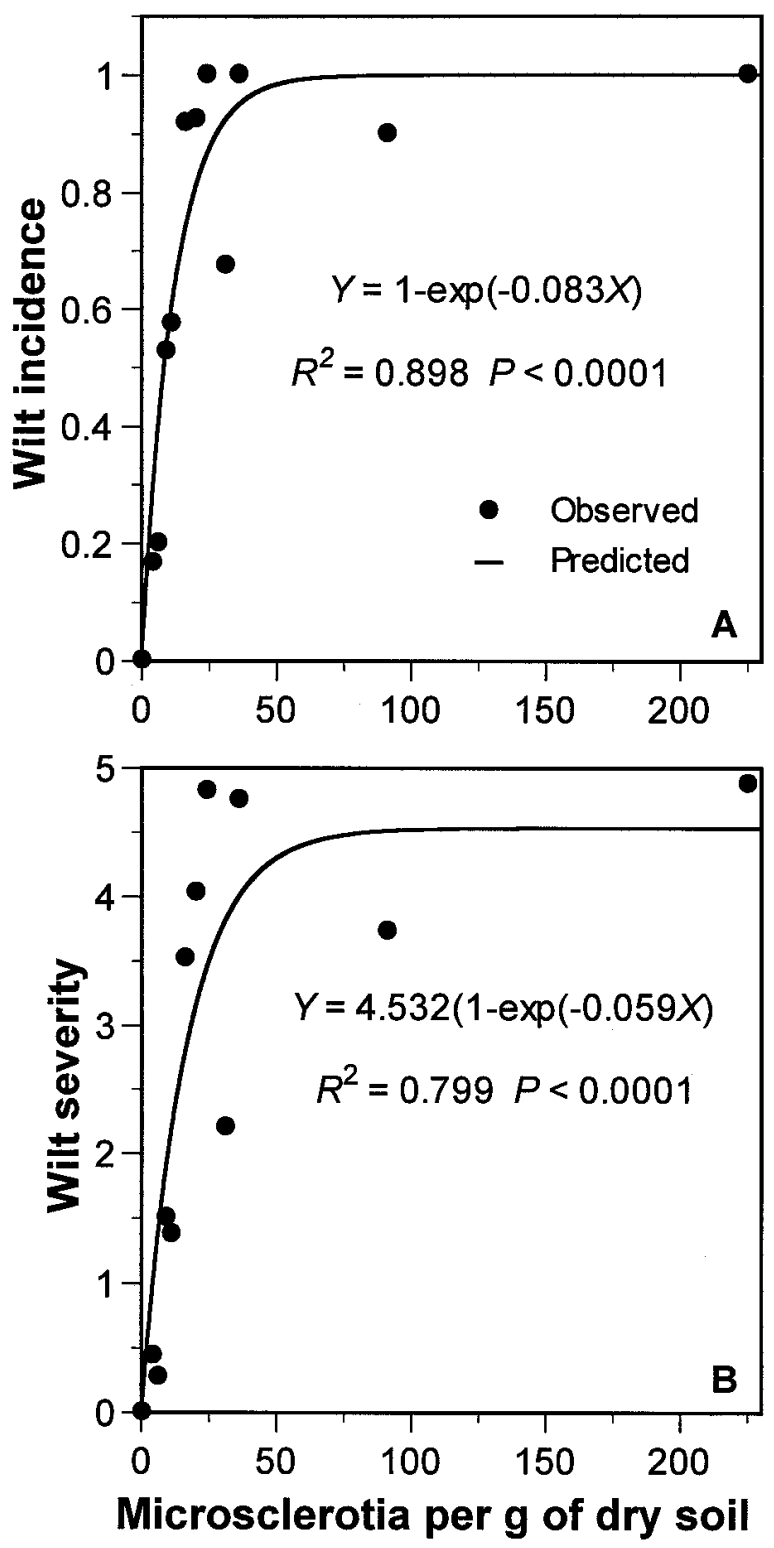

Fig. 2. Negative exponential model fitted to describe the relationships between inoculum densities of Verticillium dahliae in soil at planting and Verticillium wilt incidence and severity on cauliflower from microplot experiments in A, 1994; and B, 1995. Each data point is the mean of four replications that in turn were derived from 10 plants each. $R^{2}$ is the coefficient of determination from a linear regression analysis between observed and predicted incidence and severity values. density of 4 microsclerotia per g of dry soil caused $16 \%$ wilt incidence, and approximately 10 microsclerotia per g caused $50 \%$ wilt incidence on cauliflower (Fig. 1). Both incidence and severity increased as the inoculum density increased from 0 to 20 microsclerotia per $\mathrm{g}$ of dry soil. In 1994, wilt incidence was similar at all other higher inoculum densities except 31 microsclerotia per $\mathrm{g}$ of soil, in which it was significantly lower. In 1995, wilt incidence was not significantly different at inoculum densities above 16 microsclerotia per $\mathrm{g}$ of dry soil (Fig. 1). There was a high correlation between the number of microsclerotia in soil and wilt incidence and severity. A negative exponential model described the relationships between inoculum density in soil and wilt incidence and severity on cauliflower (Fig. 2). Coefficients of determination $\left(R^{2}\right)$ for linear regression of the observed and predicted wilt incidence and severity were $0.898(P<0.0001)$ and $0.799(P<0.0001)$, respectively. A simulation using the exponential model showed that one microsclerotium per $\mathrm{g}$ of dry soil could cause $5 \%$ wilt incidence on cauliflower. The corresponding simulated wilt severity at this inoculum density, however, was very low (0.098).

In field surveys, the inoculum density ranged from 6 to 60 microsclerotia per $\mathrm{g}$ of soil in 1994 and 16 to 90 microsclerotia per $\mathrm{g}$ of soil in 1995. Inoculum density plotted against wilt incidence over 2 years showed that wilt incidence increased with increasing inoculum density. Significant correlation between inoculum density and wilt incidence was observed, and a negative exponential model best described this relationship similar to the data from microplot experiments (Fig. 3).

Plant growth parameters. In both 1994 and 1995, the plant height, number of leaves, and dry weights of leaves and roots in the fumigated control ( $V$. dahliae undetectable) were significantly $(P \leq 0.05)$ higher than in infested treatments (Table 2). In 1994, the plant height was not significantly different between the inoculum density treatments in the range 6 to 225 microsclerotia per $g$ of soil, even though it was higher at six microsclerotia per $g$ of soil. The number of leaves at 20,91, and 225 microsclerotia per $\mathrm{g}$ of soil were significantly $(P \leq 0.05)$ lower than in other infested treatments. The dry weight of leaves at densities ranging from 20 to 225 microsclerotia per $g$ of soil was significantly $(P \leq 0.05)$ lower than at other densities, with the ex-

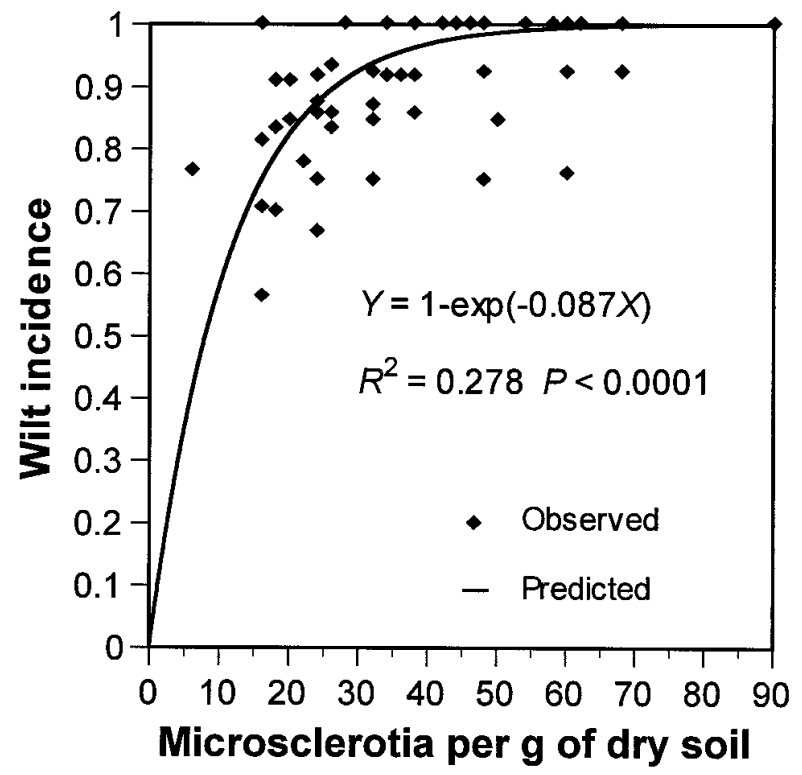

Fig. 3. Negative exponential model fitted to describe the relationships between inoculum densities of Verticillium dahliae in soil at planting and Verticillium wilt incidence and severity on cauliflower from field surveys in 1994 and 1995. Each data point is the wilt incidence from an individual 2 - by 2 -m sampling quadrat. $R^{2}$ is the coefficient of determination from a linear regression analysis between observed and predicted incidence and severity values. 
ception of 31 microsclerotia per $\mathrm{g}$ of soil. The dry weight of leaves between the fumigated control and at six microsclerotia per $g$ of soil was not significantly different. The dry weight of roots was not significantly different between the infested treatments (Table 2 ). In 1995 , the plant height was not significantly different between the infested treatments at inoculum densities in the range of 9 to 36 microsclerotia per $g$ of soil. The number of leaves at inoculum densities ranging from 16 to 36 microsclerotia per $\mathrm{g}$ of soil was similar and was significantly $(P \leq 0.05)$ lower than in other treatments. The dry weight of leaves at densities ranging from 9 to 36 microsclerotia per $\mathrm{g}$, however, was significantly lower than in other treatments. The dry weight of roots in treatments with 24 and 36 microsclerotia per $g$ of soil was significantly $(P \leq 0.05)$ lower than in other infested treatments, with the exception of 16 microsclerotia per $\mathrm{g}$ of soil (Table 2).

TABLE 2. Relationships between inoculum density of Verticillium dahliae in soil at planting and plant height, number of leaves, leaf dry weight, and root dry weight of cauliflower in microplot experiments

\begin{tabular}{cccccc}
\hline & \multirow{2}{*}{$\begin{array}{c}\text { Inoculum } \\
\text { Year }\end{array}$} & $\begin{array}{c}\text { Plant height } \\
\text { density }\end{array}$ & $\begin{array}{l}\text { No. of } \\
(\mathrm{cm})\end{array}$ & leaves & \multicolumn{2}{c}{ Dry weight $(\mathrm{g})$} \\
\cline { 1 - 3 } 1994 & 0 & $64.93 \mathrm{a}^{\mathrm{z}}$ & $18.97 \mathrm{a}$ & $112.21 \mathrm{a}$ & $23.60 \mathrm{a}$ \\
& 6 & $62.55 \mathrm{ab}$ & $17.93 \mathrm{a}$ & $112.21 \mathrm{a}$ & $19.73 \mathrm{~b}$ \\
& 11 & $58.88 \mathrm{~b}$ & $18.58 \mathrm{a}$ & $103.99 \mathrm{ab}$ & $17.73 \mathrm{~b}$ \\
& 20 & $59.21 \mathrm{~b}$ & $15.96 \mathrm{~b}$ & $81.37 \mathrm{c}$ & $16.98 \mathrm{~b}$ \\
& 31 & $58.55 \mathrm{~b}$ & $17.78 \mathrm{a}$ & $92.83 \mathrm{bc}$ & $17.27 \mathrm{~b}$ \\
& 91 & $59.35 \mathrm{~b}$ & $15.94 \mathrm{~b}$ & $80.72 \mathrm{c}$ & $17.03 \mathrm{~b}$ \\
& 225 & $59.28 \mathrm{~b}$ & $15.25 \mathrm{~b}$ & $75.67 \mathrm{c}$ & $17.23 \mathrm{~b}$ \\
& 0 & $58.65 \mathrm{a}$ & $18.93 \mathrm{a}$ & $101.38 \mathrm{a}$ & $27.70 \mathrm{a}$ \\
& 4 & $58.15 \mathrm{a}$ & $19.11 \mathrm{a}$ & $98.75 \mathrm{a}$ & $19.95 \mathrm{~b}$ \\
& 9 & $53.50 \mathrm{~b}$ & $17.23 \mathrm{~b}$ & $80.25 \mathrm{ab}$ & $19.35 \mathrm{~b}$ \\
& 16 & $51.91 \mathrm{~b}$ & $15.77 \mathrm{c}$ & $69.38 \mathrm{~b}$ & $16.55 \mathrm{bc}$ \\
& 24 & $53.10 \mathrm{~b}$ & $15.30 \mathrm{c}$ & $57.00 \mathrm{~b}$ & $14.45 \mathrm{c}$ \\
& 36 & $50.95 \mathrm{~b}$ & $14.98 \mathrm{c}$ & $54.38 \mathrm{~b}$ & $12.50 \mathrm{c}$ \\
\hline
\end{tabular}

y Inoculum density expressed as number of microsclerotia per $\mathrm{g}$ of dry soil.

${ }^{\mathrm{z}}$ All variables are means from four replications, 10 plants per replication. Numbers followed by the same letters are not significantly different within each column according to a least significant difference test $(P \leq 0.05)$.
Stomatal resistance. The repeated measures analysis of variance for stomatal resistance of leaves showed that stomatal resistance of lower (diseased) leaves were significantly $(P<0.0001)$ different among treatments in both 1994 and 1995 (Table 3). Both linear and quadratic trends of the time effects on stomatal resistance of lower, diseased leaves were also significant. There was a significant time $\times$ treatment interaction in both $1994(P<0.0003)$ and $1995(P<0.0001)$, suggesting that the slopes differed among treatments. Linear and quadratic trends were also significant within the time $\times$ treatment interaction (Table 3). Stomatal resistance in the upper leaves (without symptoms), however, were not significantly different among treatments in both $1994(P=0.2126)$ and $1995(P=$ $0.4638)$, but time effects on stomatal resistance of upper leaves were significant in both 1994 and $1995(P<0.0001)$ (Table 3).

Stomatal resistances from 5 October 1994 and 13 October 1995 have been presented as examples in Figure 4, but the relative differences between treatments on other dates were similar. In both 1994 and 1995, stomatal resistance of lower leaves from plants in the fumigated control was significantly $(P<0.05)$ lower than in infested treatments (except at four microsclerotia per $g$ of soil) (Fig. 4B and D). In 1994, stomatal resistance of lower, diseased leaves increased as inoculum level increased in the range from 6 to 31 microsclerotia per $\mathrm{g}$ of soil and was not very different between higher inoculum density treatments (Fig. 4B). In 1995, stomatal resistance of lower, diseased leaves increased as inoculum level increased in the range from 4 to 16 microsclerotia per $\mathrm{g}$ of soil, and densities above 16 microsclerotia per $\mathrm{g}$ of soil did not result in higher stomatal resistance (Fig. 4D). In upper, healthy leaves, however, stomatal resistance was not significantly different for any treatments during both years (Fig. 4A and C).

\section{DISCUSSION}

This study documents the relatively low tolerance of the cauliflower crop to $V$. dahliae microsclerotia in soil. Results suggest that even one microsclerotium per $\mathrm{g}$ of soil has the potential to infect $5 \%$ of the cauliflower plants, although the wilt severity on

TABLE 3. Repeated measures analysis of variance describing effects of inoculum levels of Verticillium dahliae in soil (microsclerotia per g of dry soil) on stomatal resistance of cauliflower leaves

\begin{tabular}{|c|c|c|c|c|c|c|c|}
\hline \multirow[b]{2}{*}{ Year } & \multirow[b]{2}{*}{ Source of variation } & \multicolumn{3}{|c|}{ Upper leaves } & \multicolumn{3}{|c|}{ Lower leaves } \\
\hline & & $d f^{x}$ & MS $^{y}$ & $P>F^{\mathrm{z}}$ & $\mathrm{df}$ & MS & $P>F$ \\
\hline \multirow[t]{9}{*}{1994} & Replication & 3 & 0.008 & 0.9663 & 3 & 12.483 & 0.8452 \\
\hline & Treatment & 6 & 0.142 & 0.2126 & 6 & 516.489 & 0.0001 \\
\hline & Time & 3 & 7.282 & 0.0001 & 3 & 770.039 & 0.0001 \\
\hline & Linear & 1 & 20.705 & 0.0001 & 1 & $2,105.001$ & 0.0001 \\
\hline & Quadratic & 1 & 0.990 & 0.0007 & 1 & 152.765 & 0.0087 \\
\hline & Time linear $\times$ treatment & 6 & 0.257 & 0.1307 & 6 & 235.500 & 0.0059 \\
\hline & Time quadratic $\times$ treatment & 6 & 0.148 & 0.0608 & 6 & 45.072 & 0.0571 \\
\hline & Time cubic $\times$ treatment & 6 & 0.057 & 0.4236 & 6 & 12.573 & 0.5994 \\
\hline & Error $_{\mathrm{b}}$ & 54 & 0.082 & & 54 & 28.801 & \\
\hline \multicolumn{8}{|l|}{1995} \\
\hline & Replication & 3 & 0.148 & 0.0833 & 3 & 17.924 & 0.055 \\
\hline & Time $\times$ replication & 6 & 0.236 & 0.0003 & 6 & 8.396 & 0.0702 \\
\hline & Time $\times$ treatment & 10 & 0.057 & 0.2050 & 10 & 36.980 & 0.0001 \\
\hline & Time linear $\times$ treatment & 5 & 0.091 & 0.2131 & 5 & 30.059 & 0.0038 \\
\hline & Time quadratic $\times$ treatment & 5 & 0.023 & 0.4337 & 5 & 43.901 & 0.0001 \\
\hline & Error $_{\mathrm{b}}$ & 30 & 0.039 & & 30 & 3.808 & \\
\hline
\end{tabular}

\footnotetext{
${ }^{x}$ Degrees of freedom.

y Mean square.

${ }^{\mathrm{z}}$ The probability values associated with the $F$ tests.
} 
these plants would be very low. In our study, a small increase in the soil inoculum density to about 4 microsclerotia per $g$ of soil could cause wilt on about $15 \%$ of cauliflower plants, and approximately 10 microsclerotia per g of soil resulted in 50\% wilt incidence with wilt severity high enough to affect productivity. Thus, low levels of soil infestation by $V$. dahliae microsclerotia could potentially pose a significant risk to cauliflower production. Any techniques used to manage this disease on cauliflower should reduce the inoculum density to very low levels. The inoculum density and wilt incidence relationships have been characterized for a number of crops $(2-5,14,15,20,21)$. Results have not been available for cool-season vegetable crops like cauliflower. Information on the association of inoculum density and wilt incidence and severity from this study could provide a basis for disease risk assessment and for developing a rational basis for the duration of crop rotation.

Under microplot conditions, generally higher wilt incidence and severity were associated with higher inoculum densities. In addition, an association between the earlier onset of $V$. dahliae infection (presence of vascular discoloration) and higher inoculum density was also observed. Not only does the higher inoculum density increase the probability of contact of cauliflower roots with microsclerotia of $V$. dahliae, but it can also result in multiple infections of a cauliflower root system. The lag between infection of adventitious roots and their progress into the vasculature of the main root is expected to be considerably shorter for multiple infections compared with solitary infections. Thus, at higher inoculum densities, cauliflower plants may be infected sooner, and therefore, disease may progress within the plant for a longer duration.

Negative exponential relationships between inoculum density of $V$. dahliae in soil at planting and wilt incidence and severity determined by the presence of vascular discoloration at harvest were observed in both microplot and field experiments. Exponential or linear relationships between inoculum density and wilt incidence have also been observed on other crops $(4,14,15,20,21)$. However, under field conditions, this relationship might vary from field to field. Inconsistent relationships between inoculum density and disease incidence have been observed on cotton in commercial fields $(5,9,10,24)$. In our study, the negative exponential relationships between inoculum density at planting and wilt incidence were variable between the field and the microplot studies. The coefficient of determination for regression between observed and predicted wilt incidence based on data from field surveys was lower than that based on data from microplot experiments. The lack of or lower correlation could have resulted from other factors that influence the wilt development including cultural practices, environmental conditions such as soil moisture and temperature, soil type, and host resistance and virulence variation of $V$. dahliae strains $(5,10$, 15). For example, in cotton, the influence of inoculum density on vascular infection or foliar symptoms may vary with the tolerance of the cultivar and with pathotypes of $V$. dahliae (defoliating and nondefoliating) (5). In Britain, Verticillium wilt on strawberry was more severe on light, sandy soils than on heavier soil types (15). All currently available cauliflower cultivars are susceptible to

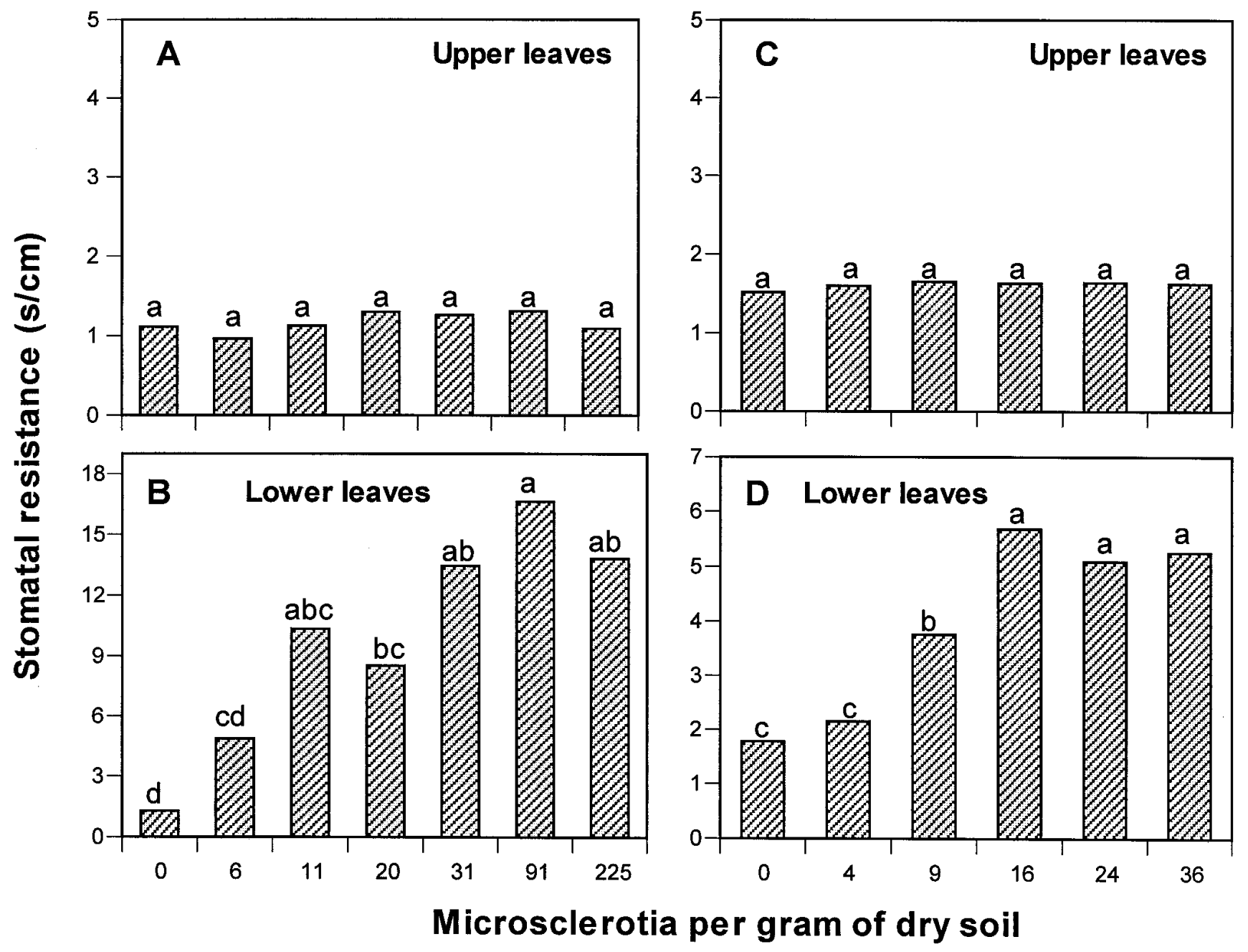

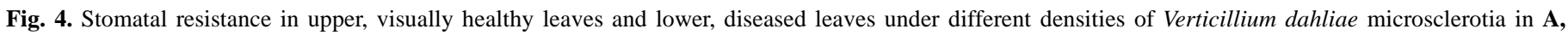

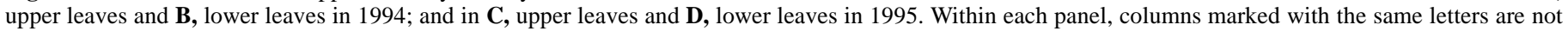
significantly different according to the least significant difference test $(P \leq 0.05)$. 
V. dahliae (27). In this study, both microplot and field experiments were conducted on the same cultivar, thus minimizing the variation from cultivars. The variation between the microplot and field experiments may have been caused by irrigation practices and uneven distribution of soil moisture in fields or by other factors.

Microsclerotia of $V$. dahliae generally occur in clustered or aggregated patterns in naturally infested commercial fields (31). This may affect the soil sampling scale for a survey in commercial fields to determine inoculum density and wilt incidence relationships (20). Our previous study on the spatial pattern of $V$. dahliae microsclerotia in soil showed that, in some cases, the cluster size of microsclerotia in soil was about 2 to $4 \mathrm{~m}$ (31). In this study, individual sampling quadrats in the field were 2 by $2 \mathrm{~m}$, which also minimized the variation arising from sampling scale.

In this study, cauliflower growth parameters at lower inoculum densities (six microsclerotia per per g of soil in 1994 and four microsclerotia per $g$ of soil in 1995) were not significantly different compared with those in fumigated controls. But significant reductions in plant growth were observed at higher inoculum densities. However, inoculum densities greater than 20 microsclerotia per $g$ of soil did not result in additional plant-growth reduction. Even though growth parameters were reduced similarly at four and six microsclerotia per $\mathrm{g}$ of soil, Verticillium wilt incidence even at four microsclerotia per $\mathrm{g}$ of soil was $16 \%$. It is, therefore, desirable for disease management methods to reduce inoculum levels to less than four microsclerotia per $g$ to minimize the number of infected cauliflower plants. Field surveys conducted previously (17) showed significant cauliflower yield reduction from Verticillium wilt. Because head size in cauliflower between plants is highly variable, accurate estimation of cauliflower yields is difficult and a large sample size is required to detect treatment differences. As there were only 10 plants in each microplot, yield losses at different densities could not be determined.

Different physiological responses to Verticillium are observed in different plant species. In potato, young, symptomless leaves from plants infected with $V$. dahliae exhibited increased stomatal resistance that reduced the $\mathrm{CO}_{2}$ exchange rate in symptomless leaves $(6,7)$. Increased stomatal resistance was also observed in both young upper and old lower leaves from cotton plants infected by $V$. dahliae (30). In alfalfa, wilt caused by $V$. albo-atrum reduced photosynthesis by lowering ribulose-1,5-biphosphate (RuBP) carboxylase activity instead of by increased stomatal resistance (22). In our study, however, increased stomatal resistance was only observed in lower, $V$. dahliae-infected leaves, not in upper, visually healthy leaves. Higher stomatal resistance in lower, diseased leaves was also associated with higher inoculum densities. This might be due to higher wilt severity at higher inoculum densities. Higher inoculum densities perhaps resulted in multiple infections, and vascular tissue was colonized earlier, resulting in the decreased hydraulic conductance in the xylem (26). Inoculum densities did not affect stomatal resistance of the upper, healthy leaves, suggesting that the extent to which $V$. dahliae reduced hydraulic conductance in young leaves on cauliflower was less than on other crops $(6,19,30)$.

In summary, this study revealed that Verticillium wilt incidence and severity on cauliflower were related to the inoculum density of $V$. dahliae in soil at planting, and a negative exponential model described this relationship. This work also demonstrated the relatively low tolerance of the cauliflower crop to $V$. dahliae inoculum levels in soil. $V$. dahliae increased stomatal resistance in diseased leaves and reduced both cauliflower shoot and root growth. Increased stomatal resistance in diseased leaves associated with higher inoculum densities not previously demonstrated in other cropping systems was observed in cauliflower. Uniform stomatal resistance on upper, healthy leaves at all densities was also observed in contrast with other hosts. Results from this study are useful in determining the relative duration of management options such as crop rotation based on the rate of inoculum attrition associated with the management option.

\section{ACKNOWLEDGMENTS}

The research was supported, in part, by California cauliflower growers. We thank J. M. Duniway for providing the porometer for stomatal resistance measurement; J. J. Hao, J. C. Hubbard, S. T. Koike, and R. X. Liebhard for assistance; and X. B. Yang for his presubmission review of the manuscript.

\section{LITERATURE CITED}

1. Anonymous. 1992. Integrated Pest Management for Cole Crops and Lettuce. Statewide Integrated Pest Management Project, University of California, Davis.

2. Ashworth, L. J., Jr., Huisman, O. C., Harper, D. M., Stromberg, L. K., and Bassett, D. M. 1979. Verticillium wilt disease of cotton: Influence of inoculum density in the field. Phytopathology 69:483-489.

3. Ashworth, L. J., Jr., and Zimmerman, G. 1976. Verticillium wilt of the pistachio nut tree: Occurrence in California and control by soil fumigation. Phytopathology 66:1449-1451.

4. Atibalentja, N., and Eastburn, D. M. 1997. Evaluation of inoculation methods for screening horseradish cultivars for resistance to Verticillium dahliae. Plant Dis. 81:356-362.

5. Bejarano-Alcazar, J., Melero-Vara, J. M., Blanco-Lopez, M. A., and JimenezDiaz, R. M. 1995. Influence of inoculum density of defoliating and nondefoliating pathotypes of Verticillium dahliae on epidemics of Verticillium wilt of cotton in southern Spain. Phytopathology 85:1474-1481.

6. Bowden, R. L., and Rouse, D. I. 1991. Effects of Verticillium dahliae on gas exchange of potato. Phytopathology 81:293-301.

7. Bowden, R. L., Rouse, D. I., and Sharkey, T. D. 1990. Mechanisms of photosynthesis decrease by Verticillium dahliae in potato. Plant Physiol. 94:1048-1055.

8. Butterfield, E. J., and DeVay, J. E. 1977. Reassessment of soil assays for Verticillium dahliae. Phytopathology 67:1073-1078.

9. Davis, J. R., Huisman, O. C., Westerman, D. T., Hafez, S. L., Everson, D. O., Sorensen, L. H., and Schneider, A. T. 1996. Effects of green manures on Verticillium wilt of potato. Phytopathology 86:444-453.

10. DeVay, J. E., Forrester, L. L., Garber, R. H., and Butterfield, E. J. 1974. Characteristics and concentration of propagules of Verticillium dahliae in air-dried field soils in relation to the prevalence of Verticillium wilt in cotton. Phytopathology 64:22-29.

11. Francl, L. J., Madden, L. V., Rowe, R. C., and Riedel, R. M. 1987. Potato yield loss prediction and discrimination using preplant densities of Verticillium dahliae and Pratylenchus penetrans. Phytopathology 77:579-584.

12. Gamliel, A., Grinstein, A., Peretz, Y., Klein, L., Nachmias, A., Tsror, L., Livescu, L., and Katan, J. 1997. Reduced dosage of methyl bromide for controlling Verticillium wilt of potato in experimental and commercial plots. Plant Dis. 81:469-474.

13. Gent, M. P., Ferrandino, F. J., and Elmer, W. H. 1995. Effects of Verticillium wilt on gas exchange of entire eggplants. Can. J. Bot. 73:557-565.

14. Grogan, R. G., Ioannou, N., Schneider, R. W., Sall, M. A., and Kimble, K. A. 1979. Verticillium wilt on resistant tomato cultivars in California: Virulence of isolates from plants and soil and relationship of inoculum density to disease incidence. Phytopathology 69:1176-1180.

15. Harris, D. C., and Yang, J. R. 1996. The relationships between the amount of Verticillium dahliae in soil and the incidence of strawberry wilt as a basis for disease risk prediction. Plant Pathol. 45:106-114.

16. Harrison, J. A. C., and Isaac, I. 1969. Effect of main stem number and lateral stem development in potato plants infected with Verticillium alboatrum and V. dahliae. Ann. Appl. Biol. 63:379-387.

17. Koike, S. T., Subbarao, K. V., Davis, R. M., Gordon, T. R., and Hubbard, J. C. 1994. Verticillium wilt of cauliflower in California. Plant Dis. 78: 1116-1121.

18. Littell, R. C., Freund, R. J., and Spector, P. C. 1991. SAS System for Linear Models. SAS Institute Inc., Cary, NC.

19. MacHardy, W. E., Busch, L. V., and Hall, R. 1976. Verticillium wilt of chrysanthemum: Quantitative relationship between increased stomatal resistance and local vascular dysfunction preceding wilt. Can. J. Bot. 54: 1023-1034.

20. Nicot, P. C., and Rouse, D. I. 1987. Relationship between soil inoculum density of Verticillium dahliae and systemic colonization of potato stems in commercial fields over time. Phytopathology 77:1346-1355.

21. Paplomatas, E. J., Bassett, D. M., Broome, J. C., and DeVay, J. E. 1992. Incidence of Verticillium wilt and yield losses of cotton cultivars (Gossypium hirsutum) based on soil inoculum density of Verticillium dahliae. Phytopathology 82:1417-1420.

22. Pennypacker, B. W., Knievel, D. P., Leath, K. T., Pell, E. J., and Hill, R. R., Jr. 1990. Analysis of photosynthesis in resistant and susceptible alfalfa clones infected with Verticillium ablo-atrum. Phytopathology 80: 1300-1306. 
23. Powelson, M. L., and Rowe, R. C. 1993. Biology and management of early dying of potatoes. Annu. Rev. Phytopathol. 31:111-126.

24. Pullman, G. S., and DeVay, J. E. 1982. Epidemiology of Verticillium wilt of cotton: A relationship between inoculum density and disease progression. Phytopathology 72:549-554.

25. Pullman, G. S., and DeVay, J. E. 1982. Epidemiology of Verticillium wilt of cotton: Effects of disease development on plant phenology and lint yield. Phytopathology 72:554-559.

26. Schnathorst, W. C. 1981. Life cycle and epidemiology of Verticillium. Pages 81-111 in: Fungal Wilt Diseases of Plants. M. E. Mace, A. A. Bell, and C. H. Beckman, eds. Academic Press, New York.

27. Subbarao, K. V., Chassot, A., Gordon, T. R., Hubbard, J. C., Bonello, P., Mullin, R., Okamoto, D., Davis, R. M., and Koike, S. T. 1995. Genetic relationships and cross pathogenicities of Verticillium dahliae isolates from cauliflower and other crops. Phytopathology 85:1105-1112.

28. Subbarao, K. V., and Hubbard, J. C. 1996. Interactive effects of broccoli residue and temperature on Verticillium dahliae microsclerotia in soil and on wilt in cauliflower. Phytopathology 86:1303-1310.

29. Tjamos, E. C. 1989. Problems and prospects in controlling Verticillium wilt. Pages 441-456 in: Vascular Wilt Diseases of Plants. E. C. Tjamos and C. Beckman, eds. Springer-Verlag, Berlin.

30. Tzeng, D. D., and DeVay, J. E. 1985. Physiological responses of Gossypium hirsutum L. to infection by defoliating and nondefoliating pathotypes of Verticillium dahliae Kleb. Physiol. Plant Pathol. 26:57-72.

31. Xiao, C. L., Hao, J. J., and Subbarao, K. V. 1997. Spatial patterns of microsclerotia of Verticillium dahliae in soil and Verticillium wilt of cauliflower. Phytopathology 87:325-331.

32. Xiao, C. L., Subbarao, K. V., Schulbach, K. F., and Koike, S. T. 1998. Effects of crop rotation and irrigation on Verticillium dahliae microsclerotia in soil and wilt in cauliflower. Phytopathology 88:1046-1055.

33. Xiao, C. L., and Subbarao, K. V. 1996. Relationships between Verticillium dahliae inoculum density, wilt incidence and severity, and growth of cauliflower. (Abstr.) Phytopathology 86:S86. 